\title{
Sinorhizobium meliloti lsrB is involved in alfalfa root nodule development and nitrogen-fixing bacteroid differentiation
}

\author{
TANG GuiRong ${ }^{1,2}$, LU DaWei $^{3}$, WANG Dong ${ }^{3} \&$ LUO Li $^{1 *}$ \\ ${ }^{1}$ State Key Laboratory of Plant Molecular Genetics, Institute of Plant Physiology and Ecology, Shanghai Institutes for Biological Sciences, \\ Chinese Academy of Sciences, Shanghai 200032, China; \\ ${ }^{2}$ University of the Chinese Academy of Sciences, Beijing 100049, China; \\ ${ }^{3}$ School of Life Science, Anhui University, Hefei 230039, China
}

Received April 7, 2013; accepted June 4, 2013; published online July 22, 2013

\begin{abstract}
Rhizobia interact with host legumes to induce the formation of nitrogen-fixing nodules, which is very important in agriculture and ecology. The development of nitrogen-fixing nodules is stringently regulated by host plants and rhizobial symbionts. In our previous work, a new Sinorhizobium meliloti LysR regulator gene $(l s r B)$ was identified to be essential for alfalfa nodulation. However, how this gene is involved in alfalfa nodulation was not yet understood. Here, we found that this gene was associated with prevention of premature nodule senescence and abortive bacteroid formation. Heterogeneous deficient alfalfa root nodules were induced by the in-frame deletion mutant of $l s r B(l s r B 1-2)$, which was similar to the plasmid-insertion mutant, $l s r B 1$. Irregular senescence zones earlier appeared in these nodules where bacteroid differentiation was blocked at different stages from microscopy observations. Interestingly, oxidative bursts were observed in these nodules by DAB staining. The decreased expression of lipopolysaccharide core genes (lpsCDE) was correspondingly determined in these nodules. S. meliloti lipopolysaccharide is required for suppression of oxidative bursts or host cell defense. These findings demonstrate that the $S$. meliloti lsrB gene is involved in alfalfa root nodule development and bacteroid differentiation by suppressing oxidative bursts or defense responses in host cells.
\end{abstract}

Sinorhizobium meliloti, LsrB, root nodule development, bacteroid differentiation, oxidative burst, lipopolysaccharide

Citation: Tang G R, Lu D W, Wang D, et al. Sinorhizobium meliloti lsrB is involved in alfalfa root nodule development and nitrogen-fixing bacteroid differentiation. Chin Sci Bull, 2013, 58: 4077-4083, doi: 10.1007/s11434-013-5960-6

Gram-negative soil bacteria, rhizobia interact symbiotically with host legumes to elicit nitrogen-fixing nodules under nitrogen-limited conditions. It is very important for sustainable agriculture and environmental conservation. During the early stages of Rhizobium-legume symbiosis, leguminous roots secrete secondary metabolites like flavonoids into soil. These flavonoids are recognized by one type of rhizobial LysR family regulators, the NodD proteins [1]. Expression of nodulation genes (nod) is then upregulated by NodD proteins to synthesize nodulation factors (NFs, chitin-lipooligosaccharides) [2]. NFs are then sensed by host plant transmembrane LysM receptor kinases, such as NFP/LYK3 of Medicago truncatula and NFR1/5 of Lotus japonicus to

*Corresponding author (email: 1luo@sibs.ac.cn) activate specific signaling pathways. A calcium spiking response is achieved and the expression of symbiosis-specific downstream genes initiates bacterial infection threads and root nodule formation. Rhizobia enter host cells along infection threads by endocytosis and differentiate into a nitrogen-fixing state (bacteroids) in mature nodules [3].

Root nodules begin senescence when a host developmental program is activated at the beginning of pod filling or under several different kinds of environmental stresses including darkness, drought, and temperature stress [4]. Leguminous root nodules exhibit differential senescence processes. Senescence of determinant root nodules (round root nodules lacking persistent meristems) on Glycine max (soybean) initiates from the inside and spreads towards the exterior. Senescence of indeterminate root nodules (com- 
posed of apical meristem zone, infection zone, and nitrogen fixing zone) on Medicago sativa (alfalfa) originates in the nitrogen-fixing zone and forms a senescent zone that moves gradually to the apical zone [4]. However, senescent root nodules have several key features as described below: (1) a color shift in the nitrogen fixation zone, appearing white or turning from pink to green due to degradation or oxidization of leghemoglobin; (2) central vacuole differentiated into multiple vesicles; (3) cytoplasm that appears less electronically dense; (4) disintegrated symbiosome membranes; (5) degraded bacteroids; and (6) resorbed symbiosomes. Infected cells decay and collapse finally. Nitrogenase activity is then significantly decreased or completely abolished [5].

Senescence of nitrogen-fixing root nodules is regulated by both symbiotic partners. In the host plant, ascorbate and glutathione play regulatory roles in delaying nodule senescence, whereas ethylene and abscisic acid promote premature nodule senescence [5]. A large number of host genes are upregulated in aging nodules, as indicated by transcriptomic data. These include a few transcriptional factors and cysteine proteases [6,7]. However, only few leguminous mutants were studied with respect to delaying or accelerating nodule senescence in detail. In bacterial symbionts, several genes are involved in the control of premature senescence among leguminous nodules. For example, $S$. meliloti $l p s B$ and $b a c A$ mutants induced early senescence in alfalfa root nodules and bacteroid differentiation was blocked or aborted $[8,9]$. The regulators of nitrogen fixation, oxygen perception, and $\mathrm{C}_{4}$-dicarboxinate transportation, NifA, FixL/ FixJ/FixK, DctB/DctD, are required for the prevention of root nodule senescence [10,11]. The sequencing of Rhizobium genomes has allowed the prediction of more regulatory genes, which gives us an opportunity to identify genes that participate in premature nodule senescence using reverse genetic methods.

In our previous work, a new $S$. meliloti LysR family gene $(l s r B)$ was identified to be essential for alfalfa nodulation and nitrogen fixation [12]. However, how this gene is involved in alfalfa nodulation was not yet understood. Here, alfalfa root nodules induced by the $l s r B$ in-frame deletion mutant $(l s r B 1-2)$ were observed in detail using microscopy; the oxidative burst in these nodules was determined by DAB staining, and the expression of LPS core genes (involved in suppression of host defense) was also analyzed. Our data suggest that $S$. meliloti $l s r B$ is associated with prevention of premature nodule senescence and abortive bacteroid formation by suppressing oxidative bursts or defense response in host cells.

\section{Materials and methods}

\subsection{Bacterial strains and growth conditions}

Escherichia coli DH5 $\alpha$ and MT616 were grown in Luria-
Bertani (LB) medium at $37^{\circ} \mathrm{C}$. Sinorhizobium meliloti 1021 and $l s r B 1-2$ were grown in LB medium supplemented with $2.5 \mathrm{mmol} \mathrm{L}^{-1} \mathrm{MgSO}_{4}$ and $2.5 \mathrm{mmol} \mathrm{L}^{-1} \mathrm{CaCl}_{2}$ $(\mathrm{LB} / \mathrm{MC})$ at $30^{\circ} \mathrm{C}$ [13]. The following antibiotics were used at indicated concentrations: $10 \mu \mathrm{g} \mathrm{mL} \mathrm{m}^{-1}$ chloramphenicol; $200 \mu \mathrm{g} \mathrm{mL}^{-1}$ neomycin; $100 \mu \mathrm{g} \mathrm{mL}^{-1}$ spectinomycin; $10 \mu \mathrm{g} \mathrm{mL}^{-1}$ tetracycline and $500 \mu \mathrm{g} \mathrm{mL}^{-1}$ streptomycin. The $S$. meliloti phage $\phi \mathrm{M} 12$ was used for general transduction [13].

\subsection{Plant nodulation test and nitrogenase activity assay}

Assays of the alfalfa nodulation on plates were carried out as described previously [12]. Assays of the alfalfa nodulation in a vermiculite-perlite $(3: 1)$ mixture were performed as described by Wang et al. [14]. Alfalfa nodule nitrogenase activity was analyzed using an acetylene $\left(\mathrm{C}_{2} \mathrm{H}_{2}\right)$ reduction method [12].

\subsection{Light, electronic and fluorescence microscopy}

The microscopic sections of alfalfa nodules were prepared and examined as by Vasse et al. [15]. The semi-thin sections were examined under an optical microscope from DME (Leica, Germany). Infection threads were labeled using $S$. meliloti constitutively expressing GFP (pHC60, [16]). Fluorescence was observed under a fluorescence microscope of DM2500-3HF-FL (Leica), and ultrathin sections were inspected under a transmission electron microscope of JEM2100 (JEOL, Japan).

\subsection{DAB staining of $\mathrm{H}_{2} \mathrm{O}_{2}$}

Three-week-old alfalfa root nodules were picked and handsectioned. The pieces of nodules were incubated into the staining solution for $30 \mathrm{~min}$ at room temperature. The solution contained $0.5 \%(\mathrm{w} / \mathrm{v})$ 3,3'diaminobenzidine (DAB) dissolved in $50 \mathrm{mmol} \mathrm{mL}^{-1} \mathrm{NaAc}$ buffer, $\mathrm{pH} 3.6$ [17]. The nodule sections were examined under an optical microscope of DME (Leica).

\subsection{DNA sequence analysis}

The deduced protein sequence of LsrB was downloaded from Sinorhizobium meliloti genome site (http://iant.Toulouse.inra.fr/bacteria/annotation/cgi/rhime.cgi). Homologs of LsrB were aligned and downloaded on NCBI Blast Microbial Genomes (http://www.ncbi.nlm.nih.gov/sutils/genom table.cgi). The phylogenetic tree was constructed using MEGA 3.1 program and the neighbor joining method was used to test the tree. The putative promoter DNA sequences were downloaded from $S$. meliloti genome server, and possible promoters were predicted by using BDGP program (http://www.fruitfly.org/seq_tools/promoter.html). 


\section{Results}

\subsection{S. meliloti $l s r B$ in-frame deletion mutant established deficient symbiosis on alfalfa plants}

The symbiotic phenotypes of $S$. meliloti $l s r B$ in-frame deletion mutant $(l s r B 1-2)$ were estimated. Three weeks after inoculation, alfalfa plants inoculated with the lsrB1-2 mutant were shorter and thinner, with more yellow leaves as compared to those inoculated with the wild type strain, $S$. meliloti 1021. The shoot biomass of these plants was significantly reduced (Figure 1(c)), and nitrogenase activity was decreased (Figure 1(b)). Alfalfa inoculated with the lsrB1-2 mutant formed slightly more nodules than those with $S$. meliloti 1021 (Figure 1(a)). These results reveal that alfalfa plants inoculated with the $l s r B 1-2$ mutant showed nitrogen starvation. When the $S$. meliloti $l s r B$ gene was expressed from a $l a c$ promoter $\left(l a c I^{Q}\right)$ of the complementation plasmid (pLGM2) in the lsrB1-2 mutant, the symbiotic deficiency of the mutant was almost rescued (Figure 1(a)-(c)). These data indicate that the $l s r B 1-2$ mutant establishes deficient symbiosis with alfalfa, which is similar to the plasmidinsertion mutant, $l s r B 1$ described before [12].

\subsection{S. meliloti lsrB1-2 mutant induced formation of deficient alfalfa root nodules}

The nitrogen starvation observed in those alfalfa plants inoculated with the $l s r B 1-2$ mutant prompted us to examine formation of infection threads and root nodule development. GFP-labeled Sinorhizobium revealed that the lsrB1-2 mutant induced normal infection threads on alfalfa seedlings like S. meliloti 1021, though a delay of one or two-day was observed. During the nodulation stages of symbiosis, the lsrB1-2 mutant elicited a large number of heterogeneous root nodules on alfalfa (Figure 2(b)-(d)). A few three-week old alfalfa nodules appeared pale pink and had a size similar to those induced by the wild type strain (Figure 2(b)), but most nodules were white and small (Figure 2(d)). Histological examination showed that pale pink nodules were fully developed, and each cell in the nitrogen-fixation zone was occupied by bacteroids, but the central vacuole was ruptured into smaller ones (Figure 2(f)). In many white nodules, a few large plant cells infected by rhizobia were surrounded by a number of small cells which contained a few bacteroids and many large starch grains (Figure 2(g)). Most of the small white nodules were composed of plant cells containing a fewer bacteroids and some starch granules (Figure 2(h)). These data indicate that $S$. meliloti $l s r B$ gene is associated with premature nodule senescence.

\subsection{S. meliloti lsrB1-2 mutant differentiated into ab- normal bacteroids in alfalfa root nodules}

The bacteroid status of bacteroids in alfalfa nodules was examined. The observation by transmission electronic microscopy showed that several $l s r B 1-2$ cells differentiated into full-length bacteroids in the nitrogen fixation zone of pale pink nodules, but the symbiosome membranes were separated from those bacteroids (Figure 3(b)). Some abortive bacteroids were visible (Figure 3(b)-(d)). In small white nodules, a fewer bacteroids were found and PHB (poly- $\beta$ hydroxybutyrate) was accumulated in them (Figure 3(c) and (d)). These senescent symptoms were not observed in threeweek old nodule cells when the nitrogen fixation zone containing S. meliloti 1021 was examined (Figures 2(a), 2(e) and 3(a)). These data demonstrate that $S$. meliloti $l s r B$ gene participates in bacteroid differentiation.

\subsection{Oxidative bursts emerged in alfalfa root nodules induced by the lsrB1-2 mutant}

Since reactive oxygen species (ROS) are involved in the regulation of leguminous nodule senescence [5], the accumulation of ROS was examined in three-week old alfalfa root nodules. DAB staining of $\mathrm{H}_{2} \mathrm{O}_{2}$ indicated that much increased levels of $\mathrm{H}_{2} \mathrm{O}_{2}$ were generated in the majority of alfalfa root nodules induced by the $l s r B 1-2$ mutant (Figure 4(b)-(c)), but only slight $\mathrm{H}_{2} \mathrm{O}_{2}$ levels were detectable in alfalfa root nodules induced by the wild type strain, $S$. meliloti 1021 (Figure 4(a)). $\mathrm{H}_{2} \mathrm{O}_{2}$ accumulation was also observed
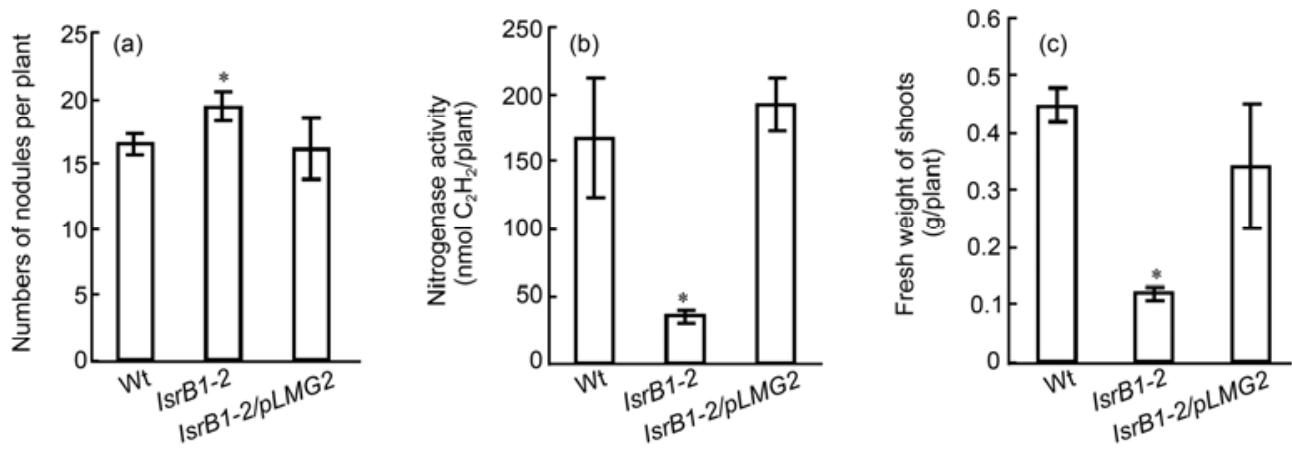

Figure 1 The lsrBl-2 mutant is deficient in symbiosis with alfalfa. As measured by average number of alfalfa nodules after three-week inoculation (a), nitrogenase activity of alfalfa nodules per plant as detected by $\mathrm{C}_{2} \mathrm{H}_{2}$ reduction (b), and biomass (fresh weight) of alfalfa shoots (c). Data from three independent experiments, mean $\pm \mathrm{SD}(n>20)$. Stars indicate significant differences as compared to the wild type strain, $S$. meliloti 1021 ( $t$-test, $P<0.05)$. 

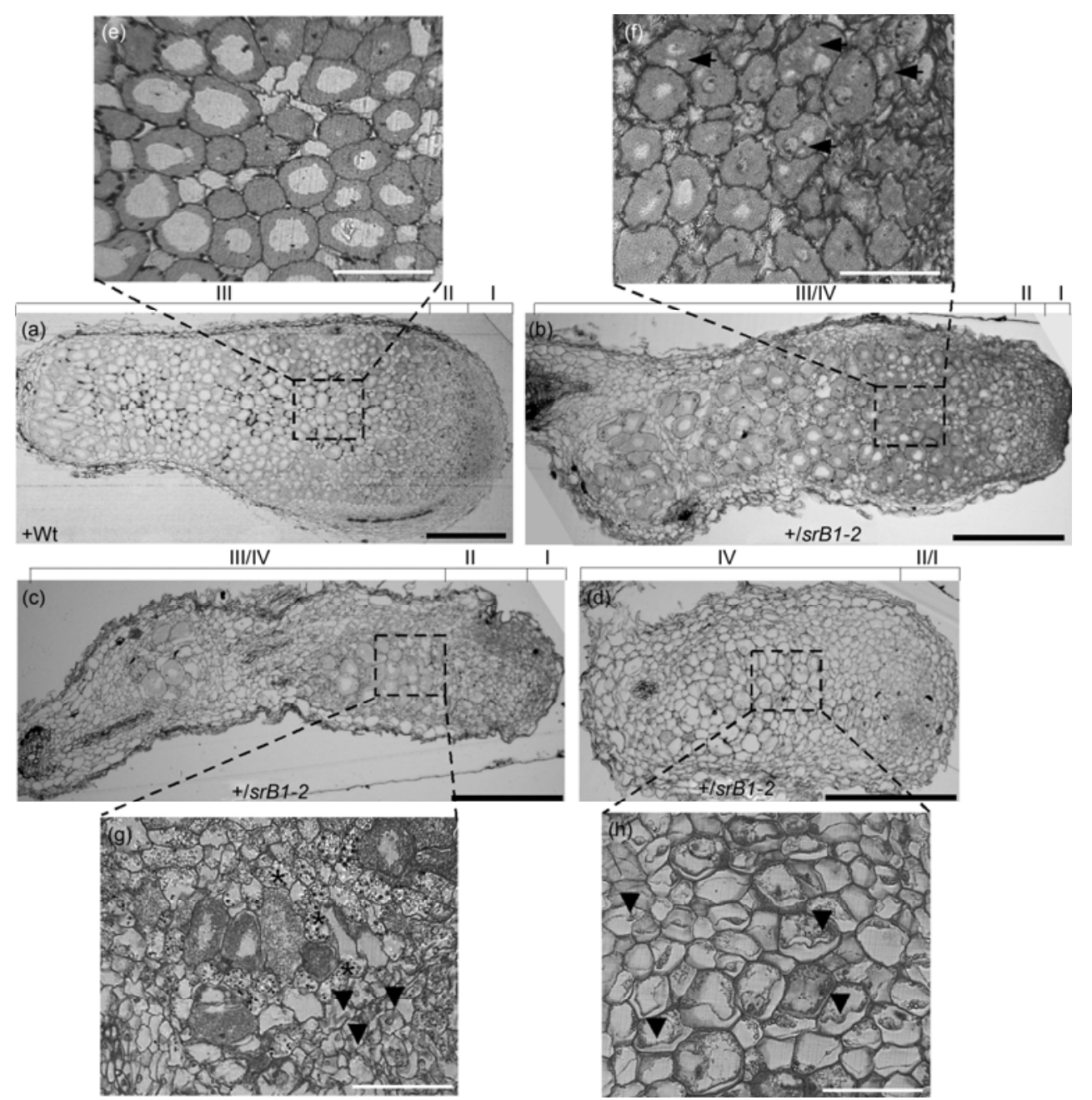

Figure 2 Premature senescence of alfalfa nodules induced by the $l s r B 1-2$ mutant. (a) A three-week nodule induced by S. meliloti 1021. (b)-(d) Three-week nodules hosting the $l s r B 1-2$ mutant. The nodule sections were observed under an optical microscope and pictures were taken by a digital camera. Squares, corresponding regions shown in (e)-(h). Arrows, ruptured vacuoles; stars, cells filled with starch granules; triangles, cells containing less content. Black bars, $200 \mu \mathrm{m}$; white bars, $50 \mu \mathrm{m}$.

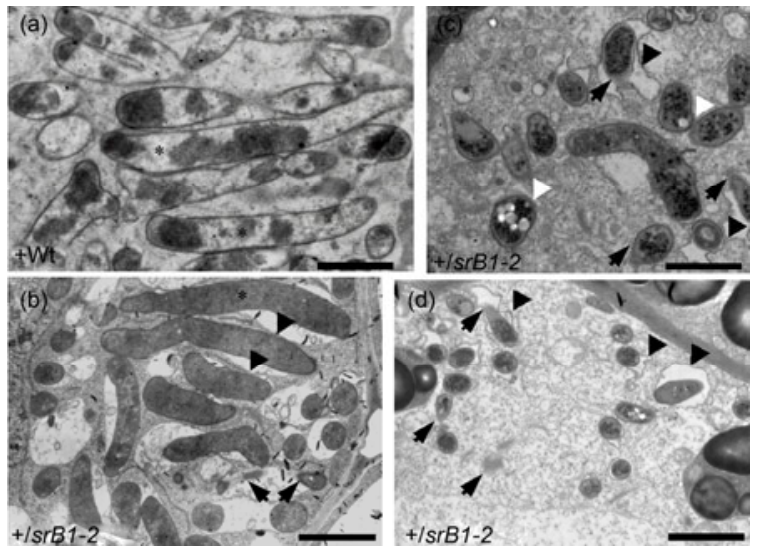

Figure 3 Bacteroid differentiation of the $l s r B 1-2$ mutant in alfalfa nodules. (a) S. meliloti 1021 bacteroids from the nitrogen fixation zone. (b)-(d) IsrB1-2 bacteroids from corresponding zone of one pale pink nodule, one large white nodule and one small white nodule. Bars, $2 \mu \mathrm{m}$; Arrows, abortive bacteroids; black triangles, separated symbiosome membranes; white triangles, granules of PHB (poly- $\beta$-hydroxybutyrate); stars, differentiated bacteroids.

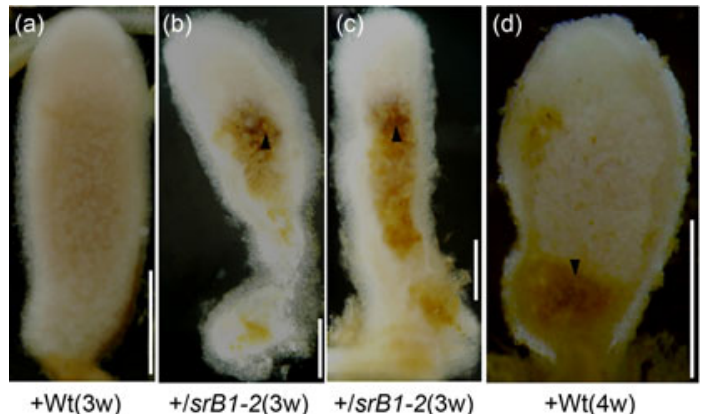

Figure $4 \quad \mathrm{H}_{2} \mathrm{O}_{2}$ accumulation assayed by DAB staining in three-week old alfalfa nodules induced by $S$. meliloti 1021 (a) and by the $l s r B 1-2$ mutant ((b) and (c)). (d) $\mathrm{H}_{2} \mathrm{O}_{2}$ accumulation in a four-week old alfalfa nodule induced by the wild type strain. Bars, $200 \mu \mathrm{m}$.

in the senescence zones of a few four-week old nodules hosting S. meliloti 1021 (Figure 4(d)). These data indicate that oxidative bursts earlier emerged in alfalfa nodules induced by the $l s r B 1-2$ mutant, which could lead to premature 
nodule senescence.

\subsection{The expression of $\operatorname{lps} C D E$ was positively regulated by $S$. meliloti LsrB in symbiosis}

It was noticed that LPS core genes, $\operatorname{lps} C D E$ are divergently located with $l s r B$, suggesting that their expression may be regulated by LsrB in $S$. meliloti. To test this possibility, the predicted promoters of $l p s C D E$ were fused with $G U S$ reporter gene, respectively. Each fusion was introduced into $S$. meliloti strains, which were then inoculated onto alfalfa seedlings. GUS activity analysis showed that the expression of $l s r B, \operatorname{trx} B, \operatorname{lrp} 3$ and $\operatorname{lps} C$ was differentially decreased in three-week old alfalfa root nodules induced by the $l s r B 1-2$ mutant compared with the wild type strain (Figure 5(a)-(h)). Quantitative analysis also confirmed that the expression of these four genes was remarkably decreased in bacteroids of the lsrBl-2 mutant (Figure $5(\mathrm{k})$ ). These data suggest that LsrB positively regulates the transcription of the $\operatorname{lps} C D E$ genes in bacteroids.

\section{Discussion}

S. meliloti LysR family gene, $l s r B$ was identified to be essential for alfalfa nodulation [12]. We try to elucidate how this Rhizobium gene works in symbiosis with its host plants using different methodologies. Here, we found that this gene played key roles in prevention of premature nodule senescence and abortive bacteroid formation, which is associated with oxidative bursts or defense responses in host cells.

LsrB belongs to the LysR transcriptional factor family that regulates the expression of diverse downstream genes to modulate different physiological processes in bacteria $[18,19]$. Therefore, we postulated that LsrB should regulate the expression of important genes that are required for symbiosis. LysR-family transcriptional factors usually regulate the expression of the divergently localized genes. Interestingly, $l p s C D E$ genes are divergently localized with $l s r B$ on the $S$. meliloti genome. $S$. meliloti lpsCDE genes encode glycotrasferases involved in biosynthesis of LPS core, which is required for efficient nodulation on alfalfa $[8,20]$. Therefore, we determined the transcripts of theses genes by RT-PCR, cloned the predicted promoters of $\operatorname{lps} C D E$, and fused them with the GUS reporter gene. The GUS activity analysis showed that the expression of $\operatorname{lps} C D E$ was decreased in the free-living $l s r B$ deletion mutant (Tang et al. unpublished data). Moreover, LsrB can bind to the conserved TN11A motif on the promoter of the lrp3-lpsCDE operon by analyses of Chromatin Immunoprecipitation (ChIP) and Electrophoresis Motility Shift Assay (EMSA) (Tang et al. unpublished data). Similar expression patterns of these genes were also detected in alfalfa nodules (Figure 5), suggesting that LsrB positively regulates the expression of these
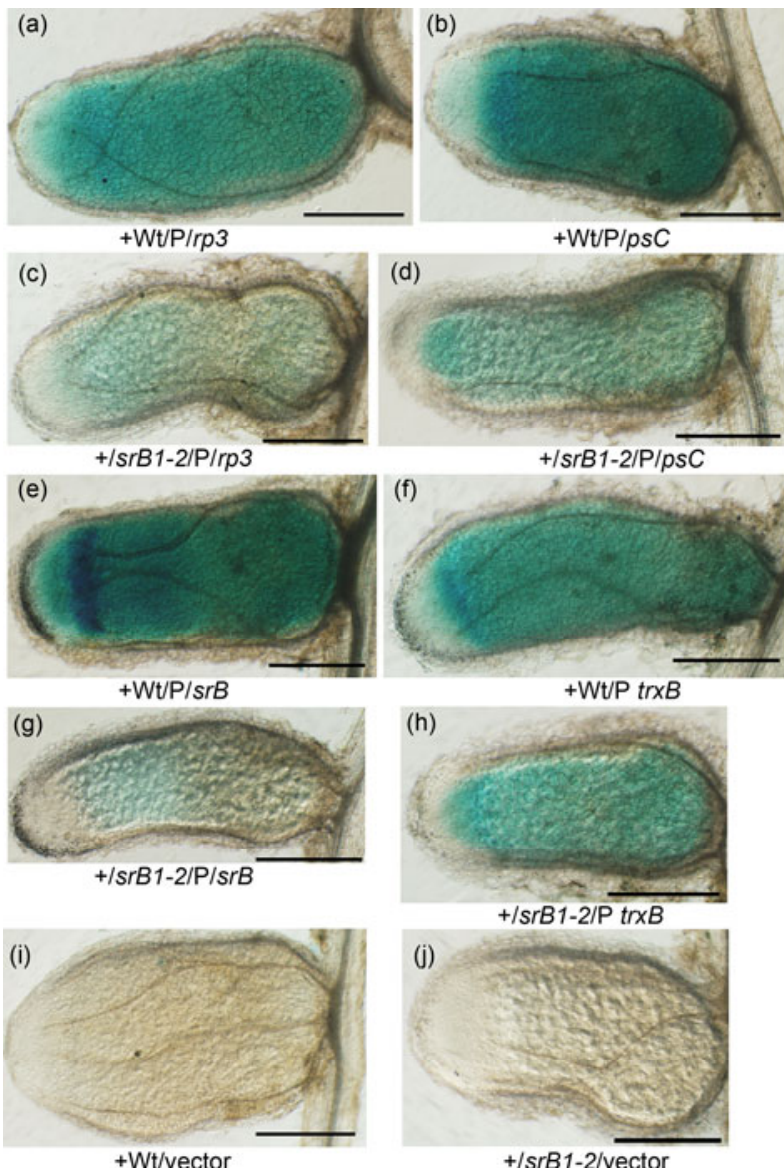

$+s r B 1-2 / P \operatorname{tr} x B$
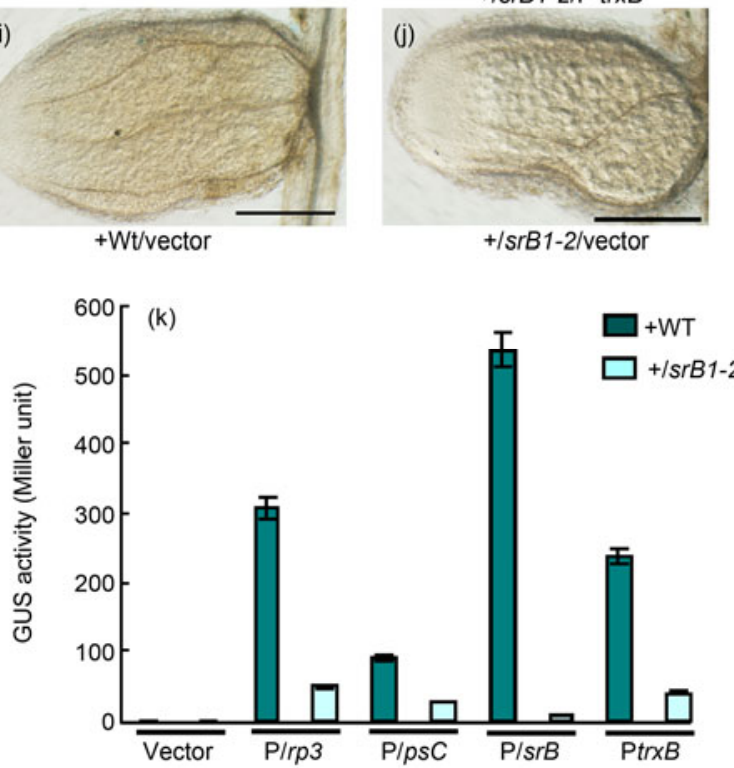

Figure 5 The expression of promoter-GUS fusions in alfalfa root nodules. (a)-(h) GUS staining of nodules induced by $S$. meliloti carrying $P_{l p s C^{-}} G U S$, $P_{l r p 3^{-}} G U S, P_{l s r B^{-}} G U S$ and $P_{t r x B^{-}} G U S$ fusions, respectively. (i) and (j) GUS staining of nodules induced by $S$. meliloti carrying the empty vector. (a), (b), (e), (f) and (i) three-week old nodules induced by S. meliloti 1021 carrying each promoter-GUS fusion or vector. (c), (d), (g), (h) and (j), three-week old nodules induced by the lsrB1-2 mutant. (k) The $\beta$-Glucuronidase activity in alfalfa nodules. Data were from three independent experiments and expressed as mean \pm SD. Vector, pRK960; Plrp3, the promoter of the $l r p 3$. Bars, $200 \mu \mathrm{m}$.

genes under both free living and symbiotic conditions. Correspondingly, less LPS was correspondingly detected from the $l s r B$ deleted cells than the wild type strain under free living conditions (Tang et al. unpublished data).

$S$. meliloti LPS is able to suppress oxidative bursts or de- 
fense responses of Medicago cells [21,22]. Interestingly, the oxidative bursts were detected in 3-week old nodules induced by the $l s r B 1-2$ mutant, which only appeared in the senescence zone of 4-week old nodule hosting the wild type strain (Figure 4). These data support that the accumulation of ROS is involved in nodule senescence. Therefore, we propose that LsrB suppresses nodule premature senescence during nodule development and bacteroid differentiation by upregulating LPS production and reducing oxidative bursts or defense response in host cells (Figure S1).

The possibility can not be excluded that LsrB positively regulates the expression of rhizobial redox- related genes (such as $\operatorname{tr} x B$, Figure 5). Their products scavenge ROS generated by both symbiotic partners. Rhizobial symbionts accumulate abundant ROS through respiration and nitrogen fixation. To protect against ROS damage, rhizobia develop ROS scavenging and antioxidant systems, which include superoxide dismutases (SOD), peroxidases, catalases, and the glutathione system [23-25]. These genes are required for the delay of premature nodule senescence. Whether their expression is regulated by LsrB needs to be further studied.

Last, genomic DNA sequence analysis showed that at least 34 homologous proteins share 55\%-99\% identity with S. meliloti LsrB, which are distributed in Sinorhizobium, Rhizobium, Mesorhizobium, Bradyrhizobium, Brucella and Bartonella species. All these proteins harbored one DNA binding domain (HTH, helix-turn-helix) and one PBP2 LTTR substrate domain. Moreover, the reconstruction of the phylogenetic tree showed that these proteins belong to one family, except the Azorhizobium caulinodans protein (Figure S2). Additionally, these proteins were clustered into two main clades on the phylogenetic tree. One clade included LsrB homolohs from Rhizobium and Sinorhizobium species, and the other consists of the proteins from Mesorhizobium, Bradyrhizobium, Brucella and Bartonella species. Altogether, these data provide an important clue that $l s r B$ homologs play a similar regulatory role in the symbioses between rhizobia and legumes, and even in the pathogenesis of Brucella and Bartonella.

In summary, S. meliloti lsrB gene is required for prevention of alfalfa nodule premature senescence and bacteroid differentiation by regulating the expression of LPS core or other downstream genes. Therefore, LsrB is a new LysR family regulator working in the later stage of symbiosis between Rhizobium and legumes.

We are grateful to Dr. Alfred Pühler for providing the plasmids of pK18mobsacB; Dr. Jun Yang and Mr. Xiaoyan Gao for helping with microscopy; Dr. Haiping Chen, Dr. Christian Stahelin and Dr. Anke Becker for critical review of the manuscript. This work was supported by National Basic Research Program of China (2010CB126501, 2011CB100702) and the National Natural Science Foundation of China (31070218).

1 Long S R. Rhizobium symbiosis: Nod factors in perspective. Plant Cell, 1996, 8: 1885-1898

2 Schultze M, Kondorosi A. Regulation of symbiotic root nodule de- velopment. Annu Rev Genet, 1998, 32: 33-57

3 Oldroyd G E, Downie J A. Coordinating nodule morphogenesis with rhizobial infection in legumes. Annu Rev Plant Biol, 2008, 59: 519-546

4 van de Velde W, Guerra J C, De Keyser A, et al. Aging in legume symbiosis. A molecular view on nodule senescence in Medicago truncatula. Plant Physiol, 2006, 141: 711-720

5 Puppo A, Groten K, Bastian F, et al. Legume nodule senescence: Roles for redox and hormone signalling in the orchestration of the natural aging process. New Phytol, 2005, 165: 683-701

6 Perez Guerra J C, Coussens G, De Keyser A, et al. Comparison of developmental and stress-induced nodule senescence in Medicago truncatula. Plant Physiol, 2010, 152: 1574-1584

7 Li Y, Zhou L, Chen D, et al. A nodule-specific plant cysteine proteinase, asnodf 32 , is involved in nodule senescence and nitrogen fixation activity of the green manure legume Astragalus sinicus. New Phytol, 2008, 180: 185-192

8 Campbell G R, Reuhs B L, Walker G C. Chronic intracellular infection of alfalfa nodules by Sinorhizobium meliloti requires correct lipopolysaccharide core. Proc Natl Acad Sci USA, 2002, 99: 3938-3943

9 Glazebrook J, Ichige A, Walker G C. A Rhizobium meliloti homolog of the Escherichia coli peptide-antibiotic transport protein sbma is essential for bacteroid development. Gen Dev, 1993, 7: 1485-1497

10 Fischer H M. Genetic regulation of nitrogen fixation in rhizobia. Microbiol Rev, 1994, 58: 352-386

11 Yurgel S N, Kahn M L. Dicarboxylate transport by rhizobia. FEMS Microbiol Rev, 2004, 28: 489-501

12 Luo L, Yao S Y, Becker A, et al. Two new Sinorhizobium meliloti lysr-type transcriptional regulators required for nodulation. J Bacteriol, 2005, 187: 4562-4572

13 Leigh J A, Signer E R, Walker G C. Exopolysaccharide-deficient mutants of Rhizobium meliloti that form ineffective nodules. Proc Natl Acad Sci USA, 1985, 82: 6231-6235

14 Wang Y, Xu J, Chen A, et al. GGDEF and EAL proteins play different roles in the control of Sinorhizobium meliloti growth, motility, exopolysaccharide production, and competitive nodulation on host alfalfa. Acta Biochim Biophys Sin, 2010, 42: 410-417

15 Vasse J, de Billy F, Camut S, et al. Correlation between ultrastructural differentiation of bacteroids and nitrogen fixation in alfalfa nodules. J Bacteriol, 1990, 172: 4295-4306

16 Cheng H P, Walker G C. Succinoglycan is required for initiation and elongation of infection threads during nodulation of alfalfa by Rhizobium meliloti. J Bacteriol, 1998, 180: 5183-5191

17 Manning V A, Chu A L, Steeves J E, et al. A host-selective toxin of Pyrenophora tritici-repentis, ptr toxa, induces photosystem changes and reactive oxygen species accumulation in sensitive wheat. Mol Plant Microbe Interact, 2009, 22: 665-676

18 Schell M A. Molecular biology of the lysr family of transcriptional regulators. Annu Rev Microbiol, 1993, 47: 597-626

19 Maddocks S E, Oyston P C. Structure and function of the lysr-type transcriptional regulator (lttr) family proteins. Microbiology, 2008, 154: 3609-3623

20 Campbell G R, Sharypova L A, Scheidle H, et al. Striking complexity of lipopolysaccharide defects in a collection of Sinorhizobium meliloti mutants. J Bacteriol, 2003, 185: 3853-3862

21 Tellstrom V, Usadel B, Thimm O, et al. The lipopolysaccharide of Sinorhizobium meliloti suppresses defense-associated gene expression in cell cultures of the host plant Medicago truncatula. Plant Physiol, 2007, 143: 825-837

22 Scheidle H, Gross A, Niehaus K. The lipid a substructure of the Sinorhizobium meliloti lipopolysaccharides is sufficient to suppress the oxidative burst in host plants. New Phytol, 2005, 165: 559-565

23 Santos R, Herouart D, Puppo A, et al. Critical protective role of bacterial superoxide dismutase in Rhizobium-legume symbiosis. Mol Microbiol, 2000, 38: 750-759

24 Sigaud S, Becquet V, Frendo P, et al. Differential regulation of two divergent Sinorhizobium meliloti genes for hpii-like catalases during free-living growth and protective role of both catalases during sym- 
biosis. J Bacteriol, 1999, 181: 2634-2639

25

Harrison J, Jamet A, Muglia C I, et al. Glutathione plays a funda- mental role in growth and symbiotic capacity of Sinorhizobium meliloti. J Bacteriol, 2005, 187: 168-174

Open Access This article is distributed under the terms of the Creative Commons Attribution License which permits any use, distribution, and reproduction in any medium, provided the original author(s) and source are credited.

\section{Supporting Information}

Figure S1 A possible model of LsrB regulating root nodule senescence.

Figure S2 Phylogenetic tree of LsrB homologs were reconstructed using an MEGA program.

The supporting information is available online at csb.scichina.com and www.springerlink.com. The supporting materials are published as submitted, without typesetting or editing. The responsibility for scientific accuracy and content remains entirely with the authors. 